\title{
Occupational Health: additional support for the aging anesthesiologist
}

\author{
Deirdre FitzGerald, MB • Alex Reid, MB • \\ Gerry Fitzpatrick, MB · Desmond O'Neill, MD
}

Received: 7 November 2014/ Accepted: 9 December 2014/Published online: 31 December 2014

(C) Canadian Anesthesiologists' Society 2014

\section{To the Editor,}

Baxter et al. provide a helpful review on the impact of work-related challenges that may be associated with elderly anesthesiologists. The authors also offer proposed assessments and possible solutions to ensure patient care is not compromised. ${ }^{1}$ This paper reflects broader concerns over a lack of preparedness among professional bodies associated with a range of liberal professions where their members may continue practice into later life without support from formal occupational health services. ${ }^{2}$ This is particularly important for medical specialities where there is a heavy reliance on psychomotor skills and rapid responses to emergent situations and where senior specialists are frequently required to attend out of hours to deal with complex clinical cases.

For this reason, it is essential that professional and regulatory bodies draw on emerging developments in research on older workers from the field of occupational health. ${ }^{3}$ The concept of "promotion of work ability" pioneered by Ilmarinen is particularly noteworthy. The basic premise is a lifespan approach with attention to work content, the work environment, as well as the individual. ${ }^{4}$

In addition to the input from regulatory bodies informed by the sciences of gerontology and occupational

\section{FitzGerald, MB ( $\square)$}

Medmark Occupational Healthcare, Cork, Ireland

e-mail: deirdrefitzgerald@physicians.ie

A. Reid, MB · G. Fitzpatrick, MB

Tallaght Hospital, Dublin, Ireland

D. O'Neill, MD

Trinity Centre for Health Sciences, Trinity College Dublin,

Tallaght Hospital, Dublin, Ireland health - we also recommend optimization of the medical care of older physicians by due consultation with specialists in geriatric medicine or old age psychiatry so that any medical conditions are treated appropriately. Where deficits are identified, we suggest use of occupational health services to facilitate assistance for older professionals who wish to continue working into later life. Such assistance may involve restrictions on their work practice so far as is possible without compromising patient care.

Finally, the form and content of continuous medical education needs to account for changing practice, habits, and educational needs of all physicians as they age. ${ }^{5}$

Funding None.

Conflict of interest None declared.

\section{References}

1. Baxter AD, Boet $S$, Reid D, Skidmore $G$. The aging anesthesiologist: a narrative review and suggested strategies. Can J Anesth 2014; 61: 865-75.

2. FitzGerald D, Keane RA, Reid A, O'Neill D. Ageing, cognitive disorders and professional practice. Age Ageing 2013; 42: 608-14.

3. O'Neill D. Ageing, the Demographic Dividend and Work. Dublin: Older \& Bolder, 2010. Available from URL: http:// www.olderandbolder.ie/sites/default/files/Creativity.pdf (accessed November 2014).

4. Ilmarinen $J$. Work ability-a comprehensive concept for occupational health research and prevention. Scand J Work Environ Health 2009; 35: 1-5.

5. Goulet F, Hudon E, Gagnon R, Gauvin E, Lemire F, Arsenault I. Effects of continuing professional development on clinical performance: results of a study involving family practitioners in Quebec. Can Fam Physician 2013; 59: 518-25. 


\section{Reply}

We recently suggested ${ }^{1}$ that aging anesthesiologists should have annual health assessments and that appropriate attention should be given to any problems identified. Fitzgerald et al. support this approach. One's health care is usually considered an individual responsibility, and it is debatable if professional bodies should be involved. Professional bodies in the UK do not appear to provide support for aging professionals continuing in the workforce, and this also appears to be the case in Canada. It is unclear if such bodies incorporate the concept of the "work ability index" from the occupational health literature as recommended by Fitzgerald et al. Health problems can clearly impact one's ability to perform clinical duties, and colleagues should be aware where relevant and with due consideration for privacy. Katlic et al.$^{2}$ recently reviewed the topic of the aging surgeon, and they described their Aging Surgeon Program that includes a comprehensive assessment (but with no mention of the use of simulation) which may be used after various triggers.

In Canada, the role of the provincial colleges appears to be limited largely to competence assessment, but the tools used are not tailored to the individual speciality. Multisource feedback has recently been added to the assessment process in some jurisdictions, but it is important to have a disciplined and objective process and not one where the assessees choose their own assessors. In the editorial that accompanied our original article, Byrick ${ }^{3}$ suggested that poor self-assessment is not limited to the elderly, and we agree. Nevertheless, Tessler's study ${ }^{4}$ suggested that the elderly are a high-risk group, and this may be a cost-effective place to start with an assessment tool focused on anesthesiology's requirements.

We also agree with Byrick's concerns about aging anesthesiologists switching to "out-of-hospital" practice and his speculation that this could increase the risk of adverse effects and compromise patient safety. We suggest that a better approach would be for provincial/national regulatory bodies to incorporate appropriate speciality- specific simulation assessments for anesthesiology (and possibly surgery?) in their competency assessments. Even if specific data on older anesthesiologists are lacking, highfidelity simulated skills, including crisis resource management, have been shown to transfer to the clinical setting. ${ }^{5}$ We suggest that an annual assessment should be performed, rather than a single assessment at age 65 as stated by Byrick, and that the default should be demonstration of competence to practice (c.f. resident assessment at the beginning of one's career). Again, we would call on national bodies, such as the Canadian Anesthesiologists' Society and the Royal College of Physicians and Surgeons of Canada, to introduce more appropriate guidelines and to suggest standards for the maintenance of competence, especially for high-risk groups such as older physicians.

Conflict of interest None declared.

\section{References}

1. Baxter AD, Boet $S$, Reid D, Skidmore $G$. The aging anesthesiologist: a narrative review and suggested strategies. Can J Anesth 2014; 61: 865-75.

2. Katlic MR, Coleman J. The aging surgeon. Ann Surg 2014; 260: 199-201.

3. Byrick $R$. The aging anesthesiologist: are we asking the right question? Can J Anesth 2014; 61: 781-6.

4. Tessler MJ, Shrier I, Steele RJ. Association between anesthesiologist age and litigation. Anesthesiology 2012; 116: 574-9.

5. Boet $S$, Bould MD, Fung L, et al. Transfer of learning and patient outcome in simulated crisis resource management: a systematic review. Can J Anesth 2014; 61: 571-82.

Alan D. Baxter MD

Sylvain Boet MD

Dennis Reid MD

Gary Skidmore MD

Department of Anesthesiology, Faculty of Medicine, Ottawa Hospital Research Institute, The Ottawa Hospital, University of Ottawa,

Ottawa, ON, Canada 